\title{
Correction to: Scaling the peak and steady-state aerobic power of running and walking humans
}

\author{
Heather M. Bowes ${ }^{1,3} \cdot$ Catriona A. Burdon ${ }^{1} \cdot$ Gregory E. Peoples $^{1} \cdot$ Sean R. Notley ${ }^{2} \cdot$ Nigel A. S. Taylor $^{1} \mathbb{D}$
}

Published online: 28 July 2021

○) Springer-Verlag GmbH Germany, part of Springer Nature 2021

\section{Correction to: European Journal of Applied Physiology https://doi.org/10.1007/s00421-021-04759-5}

The original version of this article unfortunately contained three errors. Those mistakes occurred during publication, and were not errors of the authors. The correct information is given below.

In the section "Scaling peak aerobic power", first sentence should read:

The ratio standard demonstrated a visually [Figs. 2E and 3 (dashed line)] and statistically inferior fit $(\mathrm{RMSE}=0.456$; $\mathrm{AIC}=80.033)$, when compared with the linear (Eq. 1B) and allometric models (Eq. 2B; the corresponding statistical parameters appear in subsequent paragraphs).

Equation $2 \mathrm{C}$ should read:

The original article can be found online at https://doi.org/10.1007/ s00421-021-04759-5.

Nigel A. S. Taylor

nigelastaylor@gmail.com

Heather M. Bowes

heatbowe@kth.se

Catriona A. Burdon

c.burdon@bigpond.com

Gregory E. Peoples

peoples@uow.edu.au

Sean R. Notley

snotley@uottawa.ca

1 Centre for Medical and Exercise Physiology, School of Medicine, University of Wollongong, Wollongong, NSW 2522, Australia

2 Human and Environmental Physiology Research Unit, School of Human Kinetics, University of Ottawa, Ottawa, Canada

3 Present Address: Department of Environmental Physiology, School of Technology and Health, Royal Institute of Technology, Stockholm, Sweden
Steady-state oxygen consumption

$$
=0.023\{0.014-0.037\} \times \text { mass }^{0.865\{0.759-0.982\}}
$$

In section "What then is the allometric scaling exponent for peak aerobic power in humans?", first sentence of the sixth paragraph should read.

To provide some insight into that outcome, in-house, historical data $(N=54)$ were analysed (Eq. $2 \mathrm{E})$.

The original article has been corrected.

Publisher's Note Springer Nature remains neutral with regard to jurisdictional claims in published maps and institutional affiliations. 